\title{
EL ANÁLISIS DEL IMPACTO TERRITORIAL DEL TERCER BOOM TURÍSTICO EN CANARIAS (ESPAÑA) A TRAVÉS DE LA APLICACIÓN DE UN SISTEMA DE INFORMACIÓN GEOGRÁFICA (SIG) ${ }^{1}$
}

\author{
Juan Israel García Cruz \\ Escuela Universitaria de Turismo de Santa Cruz de Tenerife
}

\section{RESUMEN}

Las Tecnologías de la Información Geográfica (TIG) son una herramienta con un gran potencial en el análisis espacial. Ante múltiples y complejos problemas territoriales, su capacidad permite dar una respuesta, siempre que su uso se plantee e implemente de forma adecuada. Así, la geografía del turismo, desde su punto de vista territorial, puede hacer uso de esta tecnología en el análisis de su dimensión territorial.

La información georeferenciada (geoinformación) permite incorporar una nueva variable al análisis del turismo. La dimensión espacial incorpora valores que enriquecen el análisis y permiten obtener resultados más completos del dinamismo territorial del fenómeno turístico, así como sus impactos territoriales.

Este trabajo hace una aproximación a la aplicación de las TIG en el análisis territorial del turismo, tomando como ejemplo el contexto del tercer boom turístico de Canarias (España), con el fin de concretar y explicar sus efectos en el territorio.

Palabras clave: Sistema de Información Geográfica; Geografía del Turismo; modelización y análisis territorial; infraestructura turística, impacto territorial.

Recibido: 22 de enero de 2014

Devuelto para su revisión: 24 de junio de 2014

Aceptado: 22 de abril de 2015

Escuela Universitaria de Turismo de Santa Cruz de Tenerife (adscrita a la Universidad de La Laguna). Grupo de Investigación ReinvenTUR: renovación e innovación turística (Universidad de La Laguna). Plaza de José Zárate Penichet, Edificio Arco Iris. 38001 SANTA CRUZ DE TENERIFE (España).E-mail: jgarciac@ull.edu.es

1 Este trabajo se enmarca en el proyecto de I+D+i denominado «Reinventur: Evaluación del impacto de las políticas públicas de renovación de destinos turísticos maduros. El caso de las Directrices de Ordenación del Turismo de Canarias» (SolSubC200801000279) financiado por la Agencia Canaria de Investigación, Innovación y Sociedad de la Información del Gobierno de Canarias y el Fondo Europeo de Desarrollo Regional (FEDER). 


\title{
Analysis of territorial impact of third tourist boom in Canary Islands (Spain) through the application of a Geographic information System (GIS)
}

\begin{abstract}
The Technologies of the Geographic Information (TGI) is a tool with great potential in spatial analysis. Faced with multiple and complex territorial issues, their ability allows a response, provided their use is implemented properly. Thus, the geography of tourism, from its territorial standpoint, can make use of this technology in the analysis of the territorial dimension of tourism.

The georeferenced information (geo-information) allows to incorporate a new variable in the analysis of tourism. The spatial dimension incorporates values that enrich the analysis and allow complete the results over the territorial dynamism of tourism as well as their territorial impacts.

This paper makes an approach to the application of TGI in the territorial analysis of tourism, using the example of the context of the third tourist boom in Canary island (Spain), to define and explain their effects on the territory.
\end{abstract}

Keywords: Geographic Information Systems; Geography of Tourism; modelling and spatial analysis; tourism facilities; territorial impact.

\section{INTRODUCCIÓN}

La actividad turística se caracteriza por una producción temporalmente coincidente con el consumo (Antón, 1998), en la medida que existe un interés por la explotación de una serie de recursos-atractivos en lugares concretos, se desarrolla la transformación de estos ámbitos con la finalidad de producir, vender y consumir bienes y servicios relacionados con la actividad turística, dando lugar a sistemas territoriales con características singulares (Vera Rebollo, 1997). En este sentido, el territorio se posiciona como fuente de recursos (naturales y culturales), factor que aporta identidad y diferenciación, condiciona aspectos como la localización de las infraestructuras o los flujos, así como es el soporte o base física para su implantación (Vera [coord.] 2011; Beas, 2012). Por ello, existe una estrecha vinculación entre la actividad y el territorio en el que se desenvuelve, haciendo que la reestructuración del sistema territorial preexistente repercuta directamente sobre su desarrollo turístico. Así, se entiende que el territorio, en relación al turismo «interactúa con las actividades existentes, contribuyendo con el correr del tiempo a su éxito o fracaso» (Pinto y Monte, 2010: 3). En definitiva, la dimensión territorial del turismo es clave para poder entender su dimensión económica y socio-cultural, construyendo un marco de conocimiento más sólido sobre este fenómeno tan complejo y diverso, facilitando así una mejor base para la gestión pública y privada de estos ámbitos.

Desde este punto de vista, el análisis espacial de variables geolocalizables y cuantificables introduce aspectos relevantes en la construcción de modelos explicativos sobre la incidencia territorial del turismo. En este sentido, los Sistemas de Información Geográfica (SIG), dentro de las Tecnologías de la Información Geográfica (TIG), facilitan las herra- 
mientas necesarias (tecnológicas, metodológicas y conceptuales) para su implementación (Bosque, 1999; Buzai y Baxendale, 2006; Buzai, 2010), desarrollando un método de trabajo en el que se busca la obtención de conocimiento contrastable mediante la medición sistemática de diferentes variables (Tapiador, 2006).

Tomando en consideración una muestra de la amplitud de trabajos que han entrado en sus aspectos teóricos (Bosque, 1992; Gutiérrez, 2000; Gómez, 2005; Peña, 2006; Buzai y Baxendale, 2006; Tapiador, 2006; Zurita, 2011), a la hora de construir un SIG hablamos de la combinación de hardware, software, datos, técnicas, procedimientos y usuarios, para poder adquirir, almacenar, editar, analizar y publica información geográfica, con el fin de dar respuesta a problemas complejos de carácter territorial, con la posibilidad de que ésta pueda ser desarrollada desde un punto de vista multidisciplinar, donde su uso desarrolla una constante evolución de sus capacidades.

A su vez, la construcción de un modelo informatizado de la realidad somete la adquisición de la información a un proceso de abstracción cartográfica y numérica (variables necesariamente localizadas en el territorio y de carácter cuantitativo), que introduce una importante limitación a considerar (Dobson, 1983, 1993; Capel, 2003, 2005 y 2009). Esto no necesariamente desvirtúa el análisis científico, ya que si son tratadas de forma adecuada, esto es, se limitan al análisis de aquello que si pueden abarcar de forma acertada, integrando sus resultados en procesos en los que entran en juego otros métodos y herramientas (análisis más amplios), se permite la construcción de modelos explicativos más completos y acertados (respuesta integral). En resumidas cuentas, es en la diversidad de enfoques y métodos donde realmente se encuentra la clave para lograr un conocimiento lo más amplio posible de aquello que pretendemos analizar, por lo que, en la medida que un problema es abarcado desde un punto de vista amplio, aplicando los enfoques y métodos más adecuados para cada variable, posteriormente puede consensuarse una respuesta más sólida y fiable.

Por todo ello, ante la rigurosidad y coherencia que exige el análisis científico, la implementación de un SIG en el análisis de la incidencia territorial del turismo, lejos del simple manejo del software informático, requiere de una base teórica y metodológica sólida que permita un uso correcto de las herramientas que ofrece. Así, a partir del planteamiento del problema, la concreción de las hipótesis y objetivos, se precisa del establecimiento de una secuencia de acciones coherente (adquisición, almacenamiento, edición y análisis), que convierta los datos recopilados en información y ésta, a su vez, en conocimiento contrastable, dando respuesta a los planteamientos que han suscitado el análisis (Capel, 2003; Buzai, 2008), pudiendo integrarse en el proceso de construcción de modelos explicativos más amplios (García, 2013). Con ello, si bien el uso de los SIG en el ámbito científico es factible, en relación a la base teórica y metodológica usada para el planteamiento del análisis y su rigurosidad, no todo aquello que se desarrolla en un SIG puede ser considerado ciencia si no se respetan estos principios.

Desde el punto de vista de la geografía del turismo, el objetivo de estudiar su dimensión territorial conlleva la toma en consideración de un formidable número de variables cuantificables. Ya sea en relación a su infraestructura, los entornos en los que se integra, las transformaciones que ejerce en los mismos, pasando por otras variables como la relación entre la población residente y turística, la planificación territorial y urbanística de 
estos ámbitos, entre otros muchos aspectos, todos ellos, en términos generales, poseen características que permiten su modelización y análisis espacial (localizable y medible de forma cuantitativa). Con ello, el análisis se enriquece con la incorporación de aspectos como la localización, distribución, asociación, disociación, interrelación, evolución, etc., elementos que pueden ser tratados de forma sistemática a través de un SIG, ampliando sus posibilidades e incrementando el conocimiento que puede obtenerse sobre la dimensión territorial del fenómeno.

En este sentido, en el ámbito de las islas Canarias, su desarrollo turístico reciente, en el contexto de un nuevo ciclo expansivo o boom turístico-inmobiliario a escala nacional y autonómica (Rullán, 1999, 2005, 2010; Blázquez y Murray, 2010; González Pérez, 2010; Hernández, 2010; Simancas, 2010; Simancas y García, 2010; Simancas, García, Dorta y Falero, 2011; García, 2013), en el que se ha implementado una política turística de carácter intervencionista (Simancas, 2010, Simancas, 2012), se ha desarrollado todo un debate en torno a su impacto económico, sociocultural y territorial. De este contexto ha surgido el desarrollo del proyecto I+D+i regional ReinvenTUR: Evaluación del impacto de las políticas públicas de renovación de destinos turísticos maduros. El caso de las Directrices de Ordenación del Turismo de Canarias. A partir de un análisis multidisciplinar, organizado en diferentes líneas de investigación interrelacionadas, se consideró adecuada la implementación de un SIG como base para el análisis de su dimensión territorial. Con ello, a través de la modelización de las principales áreas turísticas de litoral, se han extraído datos de vital interés para poder construir un modelo explicativo sobre los efectos derivados de la aplicación de una política turística autonómica, en el contexto de un ciclo económico expansivo, en el que se ha experimentado una considerable presión inmobiliaria. Así, el presente trabajo se centra en exponer la implantación y aplicación de un SIG como herramienta de apoyo en esta investigación.

\section{PLANTEAMIENTO DEL PROBLEMA: LA NECESIDAD DE APORTAR CONOCIMIENTO EN TORNO A LOS EFECTOS TERRITORIALES DEL TERCER BOOM TURÍSTICO-INMOBILIARIO A UN DEBATE MUCHO MÁS AMPLIO}

En el desarrollo de un proyecto de investigación mucho más amplio, la interrelación de las diferentes líneas de investigación facilitó la progresiva construcción de un modelo explicativo de los impactos derivados de las políticas públicas de renovación durante el último boom turístico-inmobiliario en Canarias. En este sentido, una de estas líneas se centró en la implementación de un SIG como base de adquisición y procesamiento de variables territoriales (espaciales) como herramienta que facilitase conocimiento en torno a determinados aspectos clave. De este modo, el planteamiento del problema poseía elementos comunes entre las diversas líneas de trabajo, de carácter multidisciplinar, que facilitaban la interrelación entre éstas, así como aspectos particulares que cada una debía solventar de forma independiente, aportando sus resultados al conjunto del proyecto.

Como síntesis del mismo, partimos de la concepción de que el desarrollo turístico en España se ha caracterizado por la sucesión de fases de crecimiento y declive. Éstas se comportan como límites temporales, dando lugar a lo que, de forma generalizada, se deno- 
minan «boom turísticos». Así, existe un consenso en torno al desarrollo de dos de ellos en Canarias, en consonancia con lo acontecido a escala nacional, esto es, una primera etapa entre principios de los años sesenta y finales de los setenta, y una segunda entre inicios y finales de los ochenta, ambas caracterizadas por un importante desarrollo urbanístico.

Actualmente, a escala nacional y regional, diversos autores han identificado una tercera etapa de crecimiento turístico-inmobiliario (Rullán, 1999, 2005, 2010; Blázquez y Murray, 2010; González Pérez, 2010; Hernández, 2010; Simancas, 2010; Simancas y García, 2010; Simancas, García, Dorta y Falero, 2011; García, 2013), que se ha contextualizado dentro de un escenario caracterizado por el inicio, crecimiento y explosión de una importante burbuja inmobiliaria (Fernández Durán, 2006; Artigues y Rullán, 2007; Gaja, 2008; Burriel, 2008; Blázquez y Murray, 2010; González Pérez, 2010). En el caso de Canarias, ésta podríamos situarla entre los años 1998 y 2008 (García, 2013).

En paralelo a este escenario de crecimiento turístico-inmobiliario, se llevó a cabo la progresiva implantación de una nueva política pública, de carácter dual, que ha incidido directamente sobre el desarrollo turístico de Canarias, a través de lo que algunos autores han denominado intervencionismo reglamentario (Simancas, 2012).

Así, a través de la denominada «moratoria turística» (Simancas, 2010), se establecieron medidas que trataban de racionalizar el crecimiento de nueva oferta alojativa, poniendo límites a la concesión de nuevas autorizaciones, así como prolongando en el tiempo la ejecución de una parte de los proyecto que ya contaban con ellas. Por otro, comenzaron a implantarse medidas destinadas a fomentar la renovación y recualificación del espacio urbano-turístico. En este sentido, se realizó una considerable modificación del marco normativo sectorial, implantando nuevos estándares de edificación y urbanización turística, una recualificación de la oferta (entendida desde el punto de metros cuadrados y estrellas), así como la aplicación de medidas que trataran de compensar el importante déficit de equipamientos y dotaciones existentes en las principales áreas turísticas de litoral (De Souza y Baute, 2002), vinculándolos con productos en alza en ese momento como eran el golf, el náutico o el de eventos (Consejería de Turismo y Transportes, 2003, García, 2013).

Si bien esta política pública afectaba directa y exclusivamente al uso turístico, en medio del escenario de crecimiento inmobiliario, otro uso, como es el residencial, quedaba en un segundo plano fuera de este control. La posible expansión de los procesos de residencialidad (cambio de uso de edificaciones turísticas en residenciales), así como el crecimiento de nuevas urbanizaciones residenciales ex-novo en estos mismos ámbitos, por la conversión de proyectos turísticos en residenciales (Francisco, 2003; Simancas, 2010) o la aprobación de nuevas urbanizaciones por el planeamiento municipal (Simancas y García, 2013), despertó el interés sobre su localización, caracterización y cuantificación. Este uso, formalmente fuera de lo turístico, pero informalmente desarrollado junto al mismo, cobra importancia al concentrarse en estos ámbitos preferentemente turísticos, donde cabe la posibilidad de que las nuevas edificaciones se convirtieran en un nuevo tipo de oferta (turismo residencial y alquiler vacacional) no reguladas desde lo turístico (en su defecto sometido al régimen de alquiler de temporada).

Por último, considerando que las políticas públicas en materia turística, así como los procesos de crecimiento turístico-inmobiliario, han tendido a desarrollarse con mayor incidencia en las denominadas «áreas turísticas de litoral», se precisaba de una concreción 
física que permitiera identificarlas y dimensionarlas, así como analizar dentro de ellas los procesos derivados del desarrollo de los elementos anteriormente comentados.

Con todo ello, dentro del debate abierto en torno a las posibles repercusiones socioeconómicas y territoriales de este nuevo boom turístico en Canarias (Hernández, 2010; Simancas, 2010; Simancas, García, Dorta y Falero, 2011; García, 2013), se concretaron una serie de cuestiones que se establecerían como base del diseño e implementación del SIG. Así, de forma resumida, se plantearon las siguientes:

a. Entendiendo que las políticas públicas en materia turística han tenido una mayor incidencia dentro de las comúnmente denominadas «áreas turística de litoral» ¿qué ámbitos territoriales podemos entender como tales?

b. Tratándose de áreas eminentemente turísticas, tomando en cuenta sus infraestructuras, ¿cuáles son sus principales elementos y cuál su entidad territorial?

c. En su vinculación con el contexto insular en el que se integran, ¿qué dimensión poseen a escala insular y autonómica?

d. En relación con los procesos de urbanización vinculados con el último boom, ¿han sufrido nuevos crecimiento urbanos? y, en caso afirmativo ¿qué tipo de infraestructuras lo han protagonizado?

e. Dada la aplicación de una política pública de racionalización del crecimiento de la oferta alojativa en medio de un escenario de crecimiento inmobiliario, así como de intervención sobre su categoría y tipología edificatoria, ¿se ha logrado contener el crecimiento de la oferta? y, ¿qué efectos han tenido los nuevos requerimientos edificatorios y de categoría en el conjunto de la oferta desde el punto de vista territorial?

f. Por último, en relación con los procesos de cambio de uso (turístico > residencial) o implantación de nuevas urbanizaciones residenciales, ¿qué cambios han podido desarrollarse, desde el punto de vista territorial, en la dimensión de este uso y su población vinculada?

Posicionando estas cuestiones como preguntas de la investigación, se facilitó la concreción de las hipótesis. Éstas debían fundamentarse en los principios básicos de verificación territorial de los hechos (referencia empírica y comprobable), el nivel adecuado de detalle (generalidad - especificidad), estar relacionadas con una base teórica adecuada (teoría - conceptos) y tener una formulación clara lejos de ambigüedades (operacionalidad). A partir de éstas se definieron los objetivos a lograr mediante la implementación del SIG y el análisis de la información incorporada al mismo.

Como síntesis de las hipótesis planteadas, consideramos que el tercer boom turísticoinmobiliario ha tenido una clara incidencia en las áreas turísticas de litoral en Canarias, reconocidas éstas en el planeamiento insular y municipal, pero con unos límites no completamente coincidentes con la ordenación aprobada. Los procesos de urbanización han afectado a estos ámbitos implantando nuevas infraestructuras, bajo la influencia de las políticas públicas, que han impuesto nuevos estándares y restricciones al crecimiento de la oferta alojativa turística, pero esta misma situación podría haber llevado al desvío de los proyectos urbanísticos hacia la expansión de los usos residenciales. 
Sobre este planteamiento se establecieron los objetivos de a) delimitar los espacios que pueden ser definidos como «áreas turísticas de litoral», b) caracterizarlos territorialmente, c) delimitar los procesos de crecimiento urbanístico en los mismos, d) identificar el conjunto de infraestructuras que lo han protagonizado, e) inventariar y delimitar territorialmente la oferta alojativa turística en estos ámbitos y la complementaria de ocio de mayor entidad, f) evidenciar los posibles cambios en el modelo edificatorio de la oferta alojativa y su posible crecimiento territorial, g) realizar una aproximación a la cuantificación de los crecimientos residenciales en los mismos y, h) contextualizar este proceso a escala insular y regional.

Con todo ello, se sentaron las bases que dirigirían el diseño e implementación del SIG.

\section{LA CONSTRUCCIÓN DE UN SIG COMO BASE PARA LA MODELIZACIÓN Y ANÁLISIS TERRITORIAL DE LAS PRINCIPALES ÁREAS TURÍSTICAS DE LITORAL DE CANARIAS}

La utilización de los SIG en la investigación se realiza desde un enfoque eminentemente aplicado, por lo que se busca «conocer para hacer, para actuar, para construir, para modificar» (Buzai, Baxendale y Cruz, 2009:2). En definitiva, centra su interés, no sólo en el incremento del conocimiento teórico, sino también en que dicho conocimiento aporte soluciones útiles y aplicables a la sociedad.

A grandes rasgos, en el desarrollo de un proceso de investigación, en el que se hace uso del análisis geográfico aplicado a través de un SIG, podemos establecer una secuencia en fases, como bien pueden ser las planteadas por Buzai, Baxendale y Cruz (2009), esto es: $1^{\circ}$ conceptual, $2^{\circ}$ conceptualización-metodológica, $3^{\circ}$ metodológica-técnica, $4^{\circ}$ valoración y elaboración teórica, y finalmente, $5^{\circ}$ transferencia de conocimientos.

\subsection{Fase 1. Desarrollo conceptual}

Como punto de origen, debemos ser conscientes de que el planteamiento de una investigación está sujeto al investigador, entiéndase, a su conocimiento, disciplina, valores, aspiraciones, intereses, entre otros aspectos. Por ello, existe cierto grado de subjetividad a la hora de identificar, delimitar y abarcar el análisis de un problema, lo que se ha entendido como pre-comprensión modelizante (del Rosario, 2008). En definitiva, existe una forma determinada de concebir el espacio, el tiempo y la sociedad, constituyendo un sistema de pensamiento (el marco epistémico), el cual resulta de gran influencia en la investigación (Buzai, Baxendale y Cruz, 2009), condicionando sus resultados.

Desde este punto de vista, el territorio se presenta como un sistema en el que se interrelacionan una serie de variables temáticas, con un determinado comportamiento espacial. Todo ello es enmarcado dentro de una base empírica y, por ende, observable, cuya comprensión se verá condicionada por el marco epistémico de referencia. En nuestro caso, la observación del problema y el planteamiento de su análisis ha venido dado por la base teórica aportada por la geografía del turismo, desde un punto de vista cuantitativo y la necesaria abstracción informática (modelo de datos). Ello implica restringir nuestro análisis a variables con referencia territorial, que faciliten su medición, sin que esto limite 
la posibilidad de que los resultados obtenidos puedan relacionarse con los derivados de análisis desarrollados desde otros enfoques, como así ha pretendido el proyecto ReinvenTUR con líneas de trabajo multidisciplinares.

Partiendo del planteamiento del problema realizado anteriormente, la búsqueda de las variables clave, así como las fuentes de información que nos van a permitir construirlas, parten de la necesaria abstracción de la realidad en un modelo de datos informatizado que la simplifica. Con ello, el ejercicio a realizar (diseño del SIG) se centra en este proceso de captación de forma selectiva (variables clave) y transformación (codificación informática) de la realidad territorial en un modelo informático. Como resultado, debe obtenerse un conjunto de variables temáticas que nos permitan realizar una medición sistemática de las mismas, con el fin de verificar o rechazar nuestras hipótesis, dando lugar a la obtención de conocimiento (interpretación). En caso contrario, el SIG perdería su sentido dentro de la investigación.

\subsection{Fase 2. Conceptual-metodológica}

Considerando la particular forma en la que observamos la realidad (marco epistémico), procedemos a la elección de los elementos sobre los que vamos a prestar mayor atención, esto es, todos aquellos que intervienen en el proceso de la investigación planteada (definiciones, conceptos, teorías, aplicaciones prácticas, etc.), que deben ser considerados de antemano (marco conceptual).

Es en este punto en el que entran en juego los antecedentes, tanto en el uso de SIG aplicado en el análisis, planificación y gestión turística, como teórico, en cuanto a definiciones, conceptos, y demás aspectos sobre la materia, con el fin de ser utilizados como conocimientos de partida. De igual modo, éste ejercicio nos permite verificar la relevancia y significación que pueden tener los resultados de esta investigación dentro del debate que pudiera existir al respecto.

Habida cuenta de la reducida producción científica desarrollada sobre el tercer boom turístico de Canarias (García, 2013), desde la perspectiva de la geografía del turismo, se abría la posibilidad de tratar su impacto territorial utilizando un SIG como una herramienta novedosa que facilitara la modelización y análisis de las áreas turísticas de litoral, dando lugar a una interesante aportación de conocimiento al respecto.

Para ello, considerando el planteamiento del problema y los antecedentes, se estableció la necesidad de concretar dos límites clave, esto es, el temporal y territorial.

En primer lugar, se establecieron como límites temporales aquellos que diversos autores han propuesto al tratar, bien el tercer boom turístico de forma específica, ya sea a escala nacional o autonómica, o bien el proceso de expansión inmobiliaria estrechamente vinculado con este ciclo expansivo. Este se concretó en el periodo 1998-2008. En segundo lugar, el marco espacial se centró principalmente en lo que han venido a denominarse «áreas turísticas de litoral», entendidas como ámbitos urbanos singulares caracterizados por su vocación turística y emplazadas principalmente en las islas de Tenerife, Gran Canaria, Fuerteventura y Lanzarote. Aunque su delimitación ya había sido planteada en anteriores trabajos (Cáceres, 2001), su la falta de precisión hacía necesaria una mejora sustancial. Por otro lado, con el fin de tener una referencia con la 
que poder contextualizar y valorar la entidad de los procesos identificados y medidos dentro de las áreas turísticas, se seleccionaron una serie de variables a trabajar a escala insular y regional.

Por último, se seleccionaron las variables (capas temáticas) a utilizar en el análisis, cuya concreción técnica (fuentes de información que facilitaran su construcción, modelo de datos, procesamiento, etc.) se concretarán en la siguiente fase. En este sentido, considerando los objetivos planteados, se seleccionaron un conjunto de variables agrupadas en dos bloques en función de su escala. El primero de ellos se centró en aquellas desarrolladas a escala insular o para el conjunto de la comunidad autónoma, donde se concentraron: a) ocupación del suelo, b) distribución de la población y caracterización de su perfil geo-demográfico, c) la ordenación establecida en los diferentes instrumentos territoriales y urbanísticos, y d) cambios recientes en los usos y coberturas del suelo. En un segundo bloque se concentraron aquellas variables a desarrollar a escala área turística siendo: a) la delimitación territorial de estos ámbitos, b) su caracterización mediante un mapa de ocupación del suelo más detallado, c) la delimitación de los procesos de crecimiento y transformación del entorno urbano-turístico, d) la localización y caracterización de la infraestructura turística (alojativa y complementaria) en los mismos y, e) el uso residencial.

Una vez concretados todos estos aspectos, se cierra una fase eminentemente teórica, pero de vital importancia para el correcto diseño e implementación del SIG. En su defecto, los déficits y errores en esta fase saldrían a la luz más adelante, exigiendo su replanteamiento.

\subsection{Fase 3. Metodológica-técnica}

Sobre de los aspectos teóricos resueltos con anterioridad, esta fase se centró en el diseño e implementación del modelo operacional del SIG. Éste, desde un punto de vista principalmente técnico, se concentró en dos cuestiones clave. La primera de ellas en la construcción de las variables seleccionadas a partir de las fuentes de información disponible (cartografía o datos provenientes de diversas fuentes, productos derivados de su procesamiento o fuentes directas obtenidas de procesos de inventario, etc.). La segunda, vinculada estrechamente con la anterior, se centró en establecer, a través de las propias herramientas ofrecidas por el SIG, la secuencia de procesamiento (concatenación de herramientas de edición, transformación o análisis) que debía sufrir cada variable para lograr el conocimiento pretendido (preparación y medición de forma sistemática que permitiera la obtención de conocimiento contrastable).

Con todo ello, teniendo un esquema de desarrollo no necesariamente vinculado a un proceso científico, la implementación técnica de un SIG presenta un interesante paralelismo con el esquema tradicional de articulación de una investigación (ver tabla 1).

Así, en el diseño del modelo operacional, se tomaron decisiones sobre la construcción de variables a analizar (ocupación del suelo, planeamiento, límites territoriales, oferta alojativa, complementaria y población), sintetizándose en capas temáticas, esto es, abstracciones de la realidad contenidas en un modelo de datos concreto (vectorial o raster). 


\section{Tabla 1 \\ COMPARATIVA ENTRE LAS FASES DE DESARROLLO DE UNA INVESTIGACIÓN APLICADA Y LA IMPLEMENTACIÓN DE UN SIG}

\begin{tabular}{|c|c|}
\hline Fases de desarrollo de un proyecto de Investigación & Fases para la implementación de un SIG \\
\hline $\begin{aligned} \text { Fase } 1 \text { Conceptual } \\
-\quad \text { Elección del tema. } \\
-\quad \text { Detección y planteamiento del problema. } \\
-\quad \text { Definición del objeto y modelo conceptual. }\end{aligned}$ & \begin{tabular}{|l} 
Evaluación previa de necesidades \\
$\quad-\quad$ Temáticalas a tratar. \\
$\quad$ Diagnóstico de las necesidades de infor- \\
$\quad$ mación. \\
$-\quad$ Límites geográficos, escalas y nivel de de- \\
$\quad$ talle. \\
$-\quad$ Marco temporal. \\
$-\quad$ Recursos necesarios.
\end{tabular} \\
\hline $\begin{array}{l}\text { Fase } 2 \text { Conceptual - Metodológica } \\
-\quad \text { Antecedentes. } \\
- \text { Alcance teórico y metodológico. } \\
-\quad \text { Cronograma - recursos. } \\
-\quad \text { Planteamiento de las hipótesis. } \\
-\quad \text { Diseño del objeto y modelo conceptual. }\end{array}$ & \begin{tabular}{|l} 
Diseño conceptual y lógico \\
$-\quad$ Requerimiento de información. \\
$-\quad$ Elección del Modelo de datos. \\
$-\quad$ Formas de almacenamiento y organiza- \\
$\quad$ ción de la información. \\
$-\quad$ Automatización de procesos. \\
$-\quad$ Elección de técnicas y procedimientos.
\end{tabular} \\
\hline $\begin{aligned} \text { Fase } & 3 \text { Metodológica Técnica } \\
& -\quad \text { Inventario. } \\
& -\quad \text { Organización de la información. } \\
& -\quad \text { Aplicación de las técnicas y procedimientos. } \\
- & \text { Resultados. }\end{aligned}$ & \multirow{2}{*}{\begin{tabular}{|l} 
Diseño Físico \\
$-\quad$ Inventario \\
$-\quad$ Almacenamiento y organización de datos \\
$-\quad$ Tratamiento y análisis \\
$-\quad$ Prueba piloto \\
$-\quad$ Evaluación \\
$-\quad$ Implementación definitiva del sistema
\end{tabular}} \\
\hline $\begin{aligned} \text { Fase } & 4 \text { Validación } \\
& -\quad \text { Análisis de los resultados. } \\
& -\quad \text { Contrastación de hipótesis. } \\
& -\quad \text { Obtención de un modelo explicativo. }\end{aligned}$ & \\
\hline Fase 5 Difusión, transferencia & Resultados y publicación \\
\hline
\end{tabular}

Fuente: Adaptado de (Guevara, 1992; Peña, 2006; Tomlinson, 2007; Buzai y Baxendale, 2006; Buzai, Baxendale y Cruz, 2009). Elaboración propia.

En función de las características del modelo de datos, cada variable a analizar fue sintetizada de forma particular en relación al objetivo a cumplir. En este sentido, predominó el modelo de datos vectorial, al requerirse de abstracciones en geometrías discretas, con un elevado nivel de detalle (1:1.000-1:5.000), al que asociar un considerable conjunto de atributos (ver tabla 2).

En primer lugar, con el objetivo de caracterizar cada ámbito insular, se procedió a construir tres de las variables seleccionadas, esto es: ocupación del suelo, planeamiento y población, así como se valoró positivamente la incorporación de otros dos elementos directamente desde la fuente original, como son: un modelo digital de elevaciones (MDE) que nos permitía obtener las cotas altitudinales de diferentes elementos, y la medición de cambios en los usos del suelo desarrollada por el proyecto Corine Land Cover de la Unión Europea².

2 Más información sobre esta fuente en: http://www.ign.es/ign/layoutIn/corineLandCover.do 
Tabla 2

RELACIÓN DE VARIABLES TEMÁTICAS A ANALIZAR

\begin{tabular}{|c|c|c|c|c|}
\hline 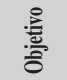 & Variable & Fuentes para su construcción & $\begin{array}{l}\text { Modelo de } \\
\text { datos }\end{array}$ & Observaciones \\
\hline \multirow{5}{*}{ 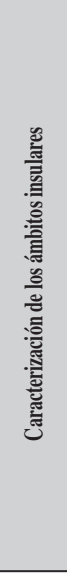 } & $\begin{array}{l}\text { Modelo Digital de } \\
\text { Elevaciones }\end{array}$ & $\begin{array}{l}\text {-Datos LIDAR } \\
\text { (coordenadas } \mathrm{x}, \mathrm{y}, \mathrm{z})\end{array}$ & Raster & $\begin{array}{l}\text { Base para el establecimiento de las cotas a } \\
\text { las que se distribuyen los diferentes usos } \\
\text { del suelo, así como la población }\end{array}$ \\
\hline & Esquemas de ordenación & $\begin{array}{l}\text {-Instrumentos de Planificación territorial (PI0, } \\
\text { PTEOTI)* } \\
\text {-Ordenación Urbanística Estructural (PG0) }\end{array}$ & $\begin{array}{l}\text { Vectorial (Polí- } \\
\text { gonos) }\end{array}$ & $\begin{array}{l}\text { Toma en consideración de las propuestas } \\
\text { de ordenación establecidas por la plani- } \\
\text { ficación territorial y planeamiento urba- } \\
\text { nístico }\end{array}$ \\
\hline & $\begin{array}{l}\text { Mapa de ocupación del } \\
\text { suelo general (Canarias) }\end{array}$ & $\begin{array}{l}\text {-Mapa Topográfico (1:1.000) } \\
\text {-Mapa Topográfico (1:5.000) } \\
\text {-Mapa Ocupación del Suelo (1:20.000) } \\
\text {-Mapa de Cultivos (parcelario catastro de rústica) }\end{array}$ & $\begin{array}{l}\text { Vectorial } \\
\text { (Polígonos) }\end{array}$ & $\begin{array}{l}\text { Localización y caracterización de los prin- } \\
\text { cipales usos y coberturas del suelo a escala } \\
\text { aproximada 1:5.000 }\end{array}$ \\
\hline & $\begin{array}{l}\text { Distribución de la } \\
\text { población (Canarias) }\end{array}$ & $\begin{array}{l}\text {-Secciones censales (INE, 2009) } \\
\text {-BBDD Población INE } \\
\text {-Callejero Digital de Canarias }\end{array}$ & $\begin{array}{l}\text { Vectorial } \\
\text { (Polígonos) }\end{array}$ & Localización y perfil geo-demográfico \\
\hline & $\begin{array}{l}\text { Evolución y cambios } \\
\text { en los usos del suelo } \\
\text { (Canarias) }\end{array}$ & $\begin{array}{l}\text { Corine Land Cover Changes } 1990 \text { - } 2000 \\
\text { Corine Land Cover Changes } 2000 \text { - } 2006\end{array}$ & $\begin{array}{l}\text { Vectorial } \\
\text { (Polígonos) }\end{array}$ & $\begin{array}{l}\text { Detección y medición de los cambios } \\
\text { acaecidos en las estructuras territoriales } \\
\text { de cada isla }\end{array}$ \\
\hline \multirow{2}{*}{ 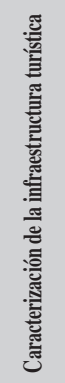 } & $\begin{array}{l}\text { Oferta Alojativa } \\
\text { Turística }\end{array}$ & $\begin{array}{l}\text {-Catastro } \\
\text {-Registro de la propiedad } \\
\text {-Mapa Topográfico (1:1.000) } \\
\text {-Ortofotografía aérea } \\
\text {-Callejero digital de canarias } \\
\text {-BBDD Turidata } \\
\text {-BBDD Cabildos Insulares } \\
\text {-BBDD Callejero Digital }\end{array}$ & $\begin{array}{l}\text { Vectorial } \\
\text { (Polígonos) }\end{array}$ & $\begin{array}{l}\text { Localización y caracterización de la oferta } \\
\text { alojativa dentro de los ámbitos delimitados } \\
\text { como área turística }\end{array}$ \\
\hline & $\begin{array}{l}\text { Oferta Complementaria } \\
\text { de Ocio }\end{array}$ & $\begin{array}{l}\text {-Catastro } \\
\text {-Mapa Topográfico (1:1.000) } \\
\text {-Ortofotografía aérea } \\
\text {-BBDD Federación Canaria de Golf } \\
\text {-BBDD Callejero Digital }\end{array}$ & $\begin{array}{l}\text { Vectorial } \\
\text { (Polígonos) }\end{array}$ & $\begin{array}{l}\text { Localización y caracterización de la oferta } \\
\text { complementaria de ocio dentro de los ám- } \\
\text { bitos delimitados como área turística }\end{array}$ \\
\hline \multirow{4}{*}{ 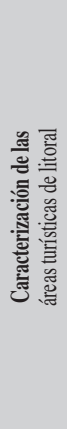 } & $\begin{array}{l}\text { Delimitación áreas } \\
\text { turísticas de litoral }\end{array}$ & $\begin{array}{l}\text {-Planificación Territorial (PIO. PTEOTI)* } \\
\text {-Mapa de ocupación del suelo general (Canarias)** }\end{array}$ & $\begin{array}{l}\text { Vectorial (Polí- } \\
\text { gonos) }\end{array}$ & $\begin{array}{l}\text { Propuesta de delimitación de las princi- } \\
\text { pales áreas turística de litoral de Canarias }\end{array}$ \\
\hline & $\begin{array}{l}\text { Mapa de ocupación del } \\
\text { suelo específico de las } \\
\text { áreas turísticas de litoral }\end{array}$ & $\begin{array}{l}\text {-Mapa de Ocupación del Suelo (SIOSE, 2005) } \\
\text {-Mapa Topográfico (1:1.000) } \\
\text {-Callejero Digital de Canarias } \\
\text {-Oferta Alojativa Turística } \\
\text {-Oferta Complementaria de Ocio }\end{array}$ & $\begin{array}{l}\text { Vectorial } \\
\text { (Polígonos) }\end{array}$ & $\begin{array}{l}\text { Estructura urbana de las principales áreas } \\
\text { turísticas de litoral de Canarias }\end{array}$ \\
\hline & $\begin{array}{l}\text { Evolución y cambios en } \\
\text { los usos del suelo (Áreas } \\
\text { turísticas) }\end{array}$ & $\begin{array}{l}\text {-Mapa Topográfico }(1: 1.000) \\
\text {-Mapa Topográfico }(1: 5.000) \\
\text {-Ortofotografía aérea } 1998 \\
\text {-Ortoexpress } 2009\end{array}$ & $\begin{array}{l}\text { Vectorial } \\
\text { (Polígonos) }\end{array}$ & $\begin{array}{l}\text { Detección y medición de los cambios } \\
\text { acaecidos en las estructuras urbanas de las } \\
\text { principales áreas turísticas de litoral }\end{array}$ \\
\hline & $\begin{array}{l}\text { Estimación de habitantes } \\
\text { y distribución en áreas } \\
\text { turísticas }\end{array}$ & $\begin{array}{l}\text {-Secciones censales (INE, 2009) } \\
\text {-BBDD Población INE } \\
\text {-Callejero Digital de Canarias }\end{array}$ & $\begin{array}{l}\text { Vectorial } \\
\text { (Polígonos) }\end{array}$ & Localización y perfil geo-demográfico \\
\hline
\end{tabular}

BBDD (Bases de datos), hace referencia a fuentes de carácter alfanumérico vinculables a la geometría.

* PIO (Plan Insular de Ordenación), PTEOTI (Plan Territorial Especial de Ordenación Turística Insular, PGO (Plan General de Ordenación).

** Hace referencia al mapa de ocupación del suelo elaborado para la investigación mediante la combinación y reclasificación de diversas fuentes cartográficas.

Fuente: Elaboración propia. 
Para la construcción de la variable ocupación del suelo, a escala insular, partimos de un método ensayado y expuesto en anteriores trabajos (García y Simancas, 2011; García, 2013) con el que se puede elaborar un mapa de ocupación a escala 1:5.000, incrementado considerablemente el nivel de detalle de los habituales mapas a 1:20.000 o 1:25.000. Para ello, tomando como base el Mapa de Ocupación del Suelo de Canarias a escala 1:20.000, elaborado por Grafcan (2002), éste se enriqueció con el cruce e incorporación de entidades poligonales extraídas de los Mapas Topográficos Digitales a escala 1:5.000 (Grafcan, 2008-2009), así como los recintos identificados con cultivo activo o sin cultivo en los diferentes mapas de cultivos de Canarias ${ }^{3}$. Siguiendo este método, con posterioridad, se procedió a clasificar los diferentes usos en función a los requerimientos de nuestra investigación (ver García, 2013). Con ello, obteníamos una fuente que nos permitía medir la entidad de los espacios urbanizados, su distribución territorial, así como establecer comparaciones entre los espacios urbano-turísticos y los no turísticos, una vez hubiéramos elaborado las delimitaciones físicas de las áreas turísticas de litoral.

Por otro lado, en la construcción de la variable planeamiento, ésta partió de la recopilación de la planimetría asociada a los Planes Territoriales Especiales de Ordenación Turística Insular o, en su defecto, Planes Insulares de Ordenación (planificación territorial), así como de las delimitaciones de suelo urbano, urbanizable y rústico en el planeamiento urbanístico vigente. Esto facilitaría la realización de dos procesos concretos. El primero, haciendo uso del planeamiento territorial, permitía una primera delimitación física de las áreas en las que se desarrolla o podría desarrollarse la actividad turística. Estas delimitaciones, en previsión de futuros crecimientos, así como dar un determinado margen de maniobra a las decisiones de implantación de las futuras infraestructuras, desarrollan una delimitación física mucho más amplia que los ámbitos urbanos consolidados en su interior. Por ello, se precisaba de una mejora en la delimitación que se realizaría en un paso posterior. El segundo, concerniente a la clasificación del suelo por el planeamiento urbanístico, nos permitió conocer la entidad y distribución, tanto del suelo urbano como urbanizable en cada ámbito insular.

Por último, para la variable población, partimos de experiencias previas en torno a este tipo de análisis desde un SIG. En concreto, sobre los procesos de residencialización y caracterización de usos residenciales en ámbitos turísticos (Simancas, Horcajada y García, 2009), teniendo desarrollos posteriores (García, 2013, Simancas y García, 2013b). Así, se recurrió a una metodología de estimación de habitantes por edificación (distribución del conjunto de habitantes de una sección censal en función del número de edificaciones residenciales y su tamaño), generalizándolo a ámbitos territoriales pequeños, que, en este caso, se centraría en una malla de 100 metros cuadrados de celda que se extiende por cada superficie insular. Para ello, los trabajos en esta materia tomaron como referencia, entre otros, los de Cai et al. (2006), CES-Canarias (2005), Wong y Lee (2005), Choi et al. (2007), Manntay et al. (2007), Wu et.al. (2008) y Lwin y Murayama (2009). Así, se obtuvo una estimación del conjunto de habitantes empadronados (reflejados en las estadísticas por sección censal) de una forma más

3 Mapa de cultivos de Canarias. Campañas: El Hierro (2005), la Palma (2003), La Gomera (2002), Tenerife (2004), Gran Canaria (2005), Fuerteventura (2003) y Lanzarote (2003. Consejería de Agricultura, Ganadería y Pesca. Gobierno de Canarias. 
detallada. A partir de esta fuente, cruzándola con elementos de apoyo, como es el MDE, se posibilitó obtener la distribución altitudinal de la población, pudiendo comparar el peso de aquella localizada en los ámbitos litorales, poniéndola en relación con los ámbitos turísticos y no turísticos de cada isla. Por otro lado, siendo utilizado como base para la realización del método anteriormente comentado, se obtuvieron variables referentes a la caracterización del perfil geodemográico (número, edad, nacionalidad, etc.), para diferentes escalas administrativas (CCAA, insular, municipal y secciones censales).

En segundo lugar, centrándonos en la escala área turística, se desarrollaron las variables referentes a la delimitación física de las mismas y su caracterización a través de la ocupación del suelo e identificación de nuevos crecimientos, así como la localización, delimitación y caracterización de la principal infraestructura turística emplazada en estos ámbitos (alojativa y complementaria de ocio) y el posible crecimiento residencial y poblacional.

La delimitación física de las áreas turísticas de litoral se concretó a partir de la relación entre el esquema de ordenación establecido por el planeamiento territorial y el mapa de ocupación del suelo desarrollado a escala insular. Su cruce nos permitió perfilar los ámbitos inicialmente delimitados por el planeamiento, pudiendo extraer aquellos espacios que realmente se encontraban ocupados por la edificación, lo que nos permitió obtener una delimitación física más acertada. Finalmente, el posterior inventario de la principal infraestructura turística permitiría terminar de perfilar estas delimitaciones.

Con respecto a la ocupación del suelo, siguiendo la metodología anteriormente expuesta a escala insular, se procesó un nuevo conjunto de fuentes que permitieran un mayor detalle en este nuevo mapa específico para las áreas turísticas de litoral. En este caso, tomando como base el Mapa de Ocupación del Suelo elaborado por el Sistema de Información de Ocupación de Suelos de 2005 (SIOSE ${ }^{4}$ ), éste se enriqueció con las entidades poligonales extraídas de los Mapas Topográficos Digitales a escala 1:1.000 (Grafcan, 2009), las entidades extraídas del Callejero Digital de Canarias (Grafcan, 2009-2010) (plazas, parques, edificios públicos, etc.) y el inventario de oferta alojativa y complementaria de ocio elaborado ad hoc. Clasificados los diferentes usos en función de los requerimientos de la investigación (ver García, 2013), se facilitó diferentes formas de clasificar los entornos urbano-turístico, con el fin de obtener mediciones concretas sobre las principales infraestructuras que lo caracterizan, su distribución, etc. (ver figura 1)

Si bien, a escala regional-insular, se consideró adecuada la utilización de los resultados obtenidos en la medición de cambios en la ocupación del suelo entre 1990 y 2006 por el proyecto Corine Land Cover, dada la escala a la que se sitúan las áreas turísticas de litoral, esta fuente no resultaba adecuada. En su defecto, mediante el uso de las bases de datos gráficas elaboradas en la investigación (variables referentes a datos principalmente de 2008 y 2009) y la ortofotografía aérea disponible, en concreto el vuelo de 1998, mediante un método combinado de clasificación de entidades (identificación de la existencia o no de cada entidad poligonal en la imagen usada como referencia) y la fotointerpretación (el uso de la ortofotografía como imagen base para la interpretación), se obtuvo una diferenciación de cada espacio urbano-turístico en función de su existencia con anterioridad o posterioridad a esa fecha (ver figura 2).

4 Para más información sobre el proyecto SIOISE: http://www.siose.es/ 
Figura 1

MAPA DE OCUPACIÓN ESPECÍFICO PARA ÁREAS TURÍSTICAS DE LITORAL (COSTA TEGUISE, LANZAROTE)

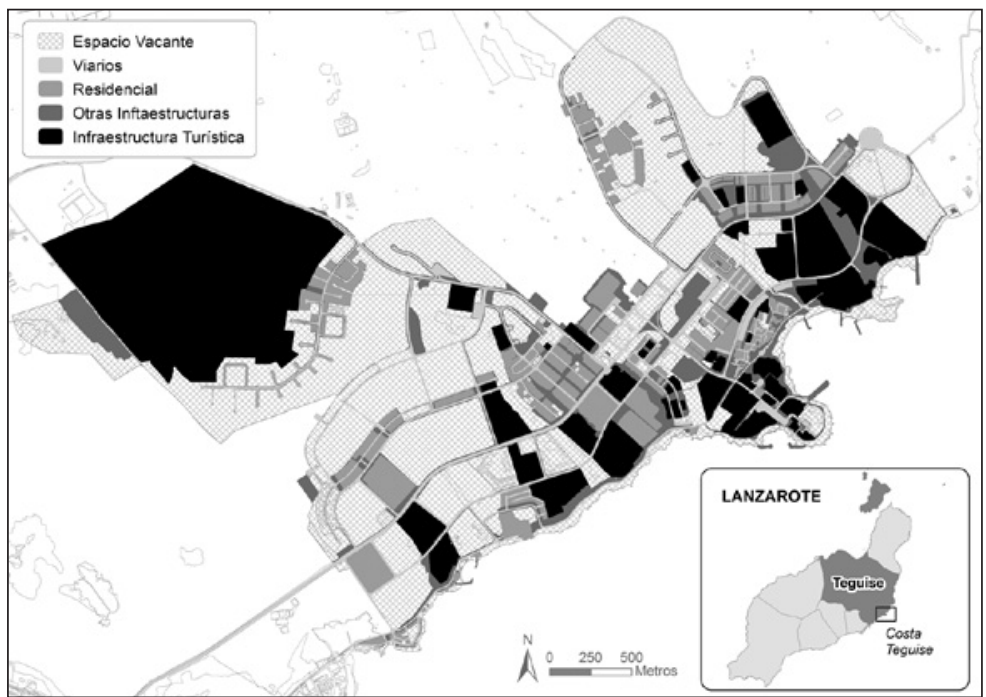

Fuente: García, 2013.

Figura 2

EVOLUCIÓN DEL ESPACIO URBANIZADO ENTRE 1998 Y 2009 (COSTA TEGUISE, LANZAROTE)

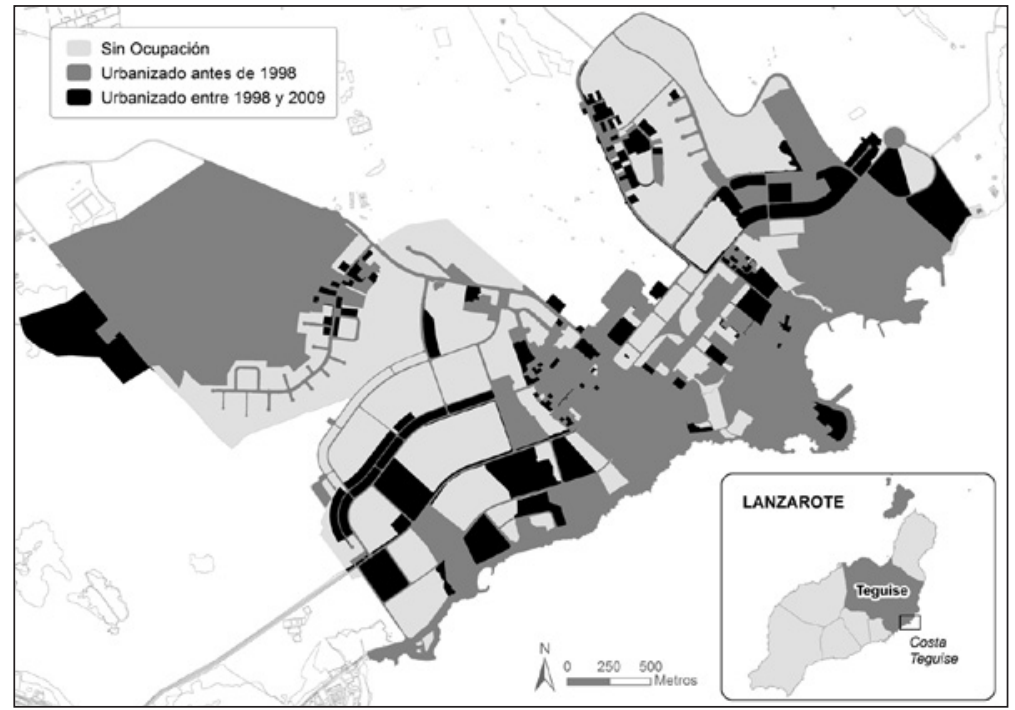

Fuente: García, 2013. 
Mediante la combinación de estas dos variables (ocupación del suelo en las áreas turísticas de litoral y evolución del espacio urbanizado entre 1998 y 2008-2009), se facilitaba la medición de varios aspectos clave. En concreto: a) se facilitó la localización de los procesos de crecimiento urbano dentro del periodo analizado, b) se permitió la medición de su entidad territorial, así como c) se hizo posible la identificación del tipo de infraestructuras que han protagonizado dicho crecimiento.

Por otro lado, directamente vinculada con las dos anteriores, la variable referente a la principal infraestructura turística se dividiría en dos grandes bloques, esto es, la oferta alojativa turística y la oferta complementaria de ocio. En primer lugar, sobre la base de una metodología de sistematización de la oferta en un SIG ya expuesta en otras publicaciones (García, Simancas y Dorta, 2013; García, 2013), su inventario supuso la revisión de la información oficial existente sobre la oferta alojativa. Partiendo de ésta (Sistema Informático Turístico del Gobierno de Canarias, Cabildo Insulares, Callejero Digital de Canarias y Catastro.), se procedió a la localización y delimitación territorial de cada infraestructura alojativa turística, así como su caracterización a través de atributos clave (tipología, modalidad, categoría, plazas alojativas, año de construcción, etc.). Del mismo modo, se procedió de forma similar con la oferta complementaria de ocio de mayor entidad (parques temáticos, centros comerciales, museos, etc.), procediendo a su delimitación cartográfica y caracterización de forma básica (tipología, año de construcción, etc.) (ver figura 3).

\section{Figura 3}

INVENTARIO DE LA OFERTA ALOJATIVA Y OFERTA COMPLEMENTARIA DE OCIO (COSTA TEGUISE, LANZAROTE)

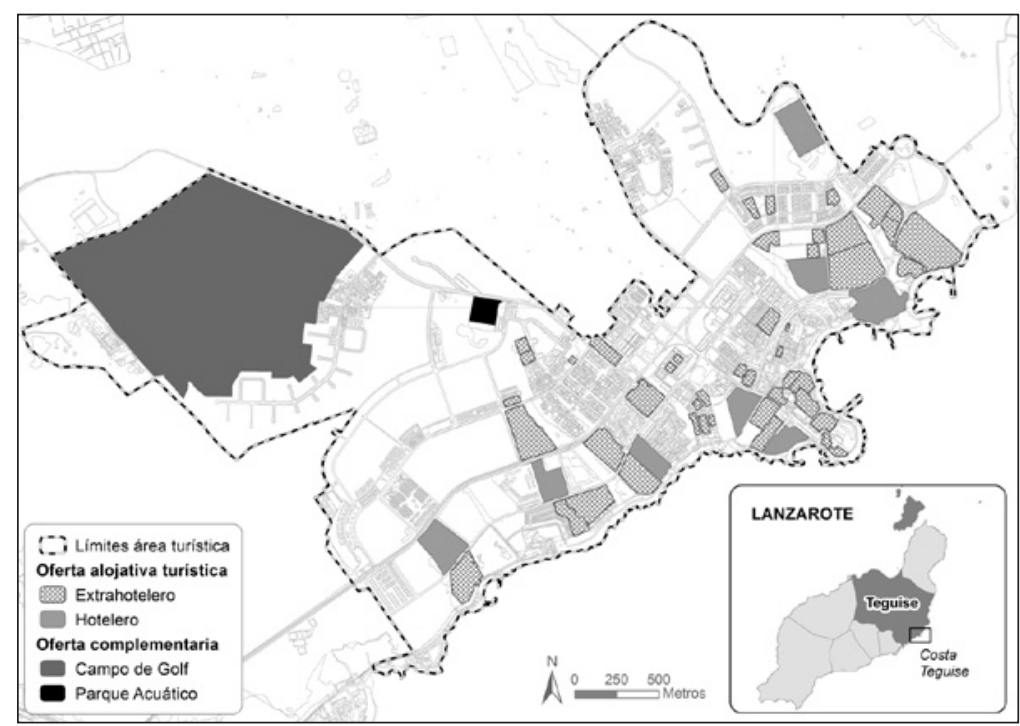

Fuente: García, 2013. 
Estas dos variables permiten realizar una caracterización de las principales infraestructuras turísticas de estos ámbitos, ya sea mediante la consideración de la antigüedad, tamaño, modalidad, clasificación o categoría de la oferta alojativa turística o la tipología, tamaño y antigüedad de la oferta complementaria de ocio.

Por último, en relación con la variable población, se procedió a la repetición del método anteriormente descrito a escala insular en cada una de las áreas turísticas de litoral delimitadas (incrementando el nivel de detalle). Obtenidas, tanto la caracterización geodemográfica de cada sección censal, así como la distribución de la población en una malla de 100 metros cuadrados de celda, estos datos se vincularon con la identificación de usos residenciales en el mapa de ocupación realizado de forma específica para estos ámbitos, obteniendo una primera aproximación a los crecimiento de este uso y su población vinculada, estableciendo tipologías (ver Simancas y García, 2013b y García 2013).

\subsection{Fase 4. Validación y elaboración teórica}

Una vez implementado el SIG, contando con todas las variables seleccionadas para el análisis, se procedió a la aplicación de los procesos previstos para la obtención, mediante mediciones sistemáticas, del conocimiento necesario (interpretación de los datos) para cumplir con nuestros objetivos y lograr verificar o rechazar nuestras hipótesis. Éstos, expuesto con mayor detalle en García (2013), se centraron en la aplicación de herramientas de geoporcesamiento y análisis espacial a las variables seleccionadas de forma independiente, así como realizando cruces entre éstas para la obtención de resultados más elaborados. Cada rutina de trabajo (concatenación de herramientas) fue diseñada con el fin de obtener las mediciones necesarias para cumplir con los requerimientos previstos en el planteamiento de la investigación, llevando a la comprobación empírica aquellos aspectos que previamente habían sido planteados en lo teórico.

Esta aplicación evidencia como el análisis espacial permite incorporar al a-espacial la posibilidad de tomar en consideración las relaciones existentes entre las entidades de una misma variable (ej. concentración de la oferta alojativa turística), o con otras variables (ej. el tipo de infraestructura que se localiza dentro de los ámbitos urbanizados entre 1998 y 2008). Con ello, elementos como la localización, distribución, asociación, interrelación o la evolución de las variables escogidas para el análisis se convirtieron en aspectos clave para lograr una respuesta fiable a los interrogantes que han estructurado la investigación.

Aun así, si bien la información extraída de este proceso permite conocer el ¿Qué?, ¿Cómo?, ¿Dónde?, ¿Cuándo?, ¿Quién?, etc., para poder llegar a un modelo explicativo completo, esto es, el ¿Por qué?, se precisa de su puesta en común con el conocimiento procedente del análisis realizado por otras disciplinas. Así, dentro del contexto del proyecto de investigación multidisciplinar en el que se integró el SIG, a través del análisis económico se aportaron las bases para entender el ciclo expansivo en el que se contextualiza el tercer boom turístico; a través del derecho, los fundamentos que han estructurado la política turística aplicada durante el mismo; de la sociología y antropología el comportamiento de los principales agentes (sociales, políticos y económicos) implicados, así como de la arquitectura, ingeniería de la edificación y ciencias afines, entender los cambios en las tipologías edificatorias y for- 
mas de urbanización. Con todo ello, se hizo posible la elaboración de un modelo que logró dar una respuesta sólida y fiable a los interrogantes que habían movido esta investigación.

En este punto, como síntesis de los resultados obtenidos ${ }^{5}$, ponemos en relación los planteamientos iniciales con los resultados obtenidos de la explotación del SIG.

a) Haciendo uso de cada ámbito insular como escenario en el que contextualizar el posible desarrollo turístico-inmobiliario de las áreas turísticas de litoral, a través de la explotación de las variables a escala insular: ocupación, planeamiento y población, obtenemos datos que nos permiten realizar esta primera lectura. Así, partiendo de una superficie de $7.440 \mathrm{Km}^{2}$ para el conjunto de Canarias, se concretó que los espacios urbanizados suponían el $6 \%\left(460,5 \mathrm{Km}^{2}\right)$, frente al $10 \%$ bajo uso agrícola $\left(743,6 \mathrm{Km}^{2}\right)$ y el $84 \%$ restante repartido entre formaciones vegetales y suelo descubierto (estructuras volcánicas en su mayoría).

Localizado principalmente en el litoral, el desarrollo turístico-inmobiliario ha vuelto a tener un importante papel en el proceso de artificialización de la costa. En este sentido, de los aproximadamente $130,1 \mathrm{Km}^{2}$ afectados por procesos de cambio de uso en el conjunto del archipiélago durante periodo 1990-2006, más del 50\% se localizaron por debajo de la cota 100 metros, coincidiendo con la ubicación de las principales áreas urbanas de las islas, incluidas las turísticas. Estos cambios de uso se concentraron en un $52 \%$ en procesos de urbanización, a los que se le podía vincular un $12 \%$ más identificado en su momento como movimientos de tierras asociados a obras de construcción.

La continuidad de este proceso de concentración humana en el litoral quedaba reflejado en indicadores como la distribución del suelo urbano y urbanizable por debajo de la cota 100 metros. En este sentido, el 50\% del suelo urbanizable existente en las islas (2001) se localizaba por debajo de esta cota, así como el $45 \%$ del suelo clasificado como urbano.

Derivado de todo ello se estimó, que en el año 2009, en esta franja de altura en las islas turísticas (Tenerife, Gran Canaria, Fuerteventura y Lanzarote), se concentraban aproximadamente 920.442 habitantes (el $42,5 \%$ de Canarias).

b) En lo que respecta a la delimitación de las áreas turísticas de litoral, tomando en consideración los esquemas de ordenación establecidos por el planeamiento territorial, la delimitación física que realizan pudo ajustarse haciendo uso de la concreción del espacio realmente urbanizado dentro de los mismos, a través del mapa de ocupación del suelo, pudiéndolos perfilar aún más mediante la localización de las principales infraestructuras turísticas (oferta alojativa y complementaria de ocio). Así, del procesamiento realizado de estas variables en el SIG se obtuvo una delimitación más ajustada con la realidad territorial de las «áreas turísticas de litoral». Considerando estos espacios, en relación con los ámbitos insulares en los que se integran, así como el conjunto de la comunidad autónoma, actualmente suponen el $1,8 \%$ de la superficie del archipiélago (el 18,3\% de la superficie urbanizada en las islas, el $57 \%$ de la superficie urbanizada por debajo de la cota 100 metros).

5 Para consultar una versión más extendida y detallada del mismo ver García (2013). 
c) Partiendo de estos ámbitos, la delimitación y diferenciación del espacio urbanizado antes de 1998, de aquel desarrollado entre esta fecha y 2008-2009, permitió concretar la dimensión territorial del último proceso de crecimiento turístico-inmobiliario en los mismos. Con ello, se verificó que las principales áreas turísticas de litoral habían incrementado su tamaño en $29,4 \mathrm{Km}^{2}$, presentando una tasa de crecimiento del $56 \%$.

d) Considerando estos ámbitos como espacios turístico-urbanos singulares, a través del mapa de ocupación realizado de forma específica para los mismos, en el que se integró el inventario de oferta alojativa y la principal oferta complementaria de ocio, se hizo posible su caracterización territorial. Así, en relación con un cambio de tendencia, apoyado por la regulación de nuevos estándares para la urbanización y edificación ${ }^{6}$, como uno de los factores de crecimiento de estos espacios, se evidenció una evolución en las formas de urbanización turística. Ésta se caracterizó por la reducción de la densidad edificatoria en favor de un mayor porcentaje de espacios libres, pero suponiendo a su vez un mayor desarrollo en extensión superficial. Desde el punto de vista de la oferta alojativa, se identificó una transición desde la tradicional tipología edificatoria vertical de reducida superficie, a una tipología de reducida altura y mayor extensión horizontal, suponiendo un incremento de la superficie por plaza alojativa $\left(60 \mathrm{~m}^{2} /\right.$ plaza) que llega a duplicar a la desarrollada en los dos booms turísticos anteriores (2030 m³/plaza) (Simancas y García, 2010; García, 2013) (ver figura 4). Con ello, aunque el número de establecimientos alojativos turísticos autorizados e implantados en este periodo de tiempo fue inferior al previsto inicialmente, considerando el número de autorizaciones vigentes (Simancas, 2010; García, 2013), su extensión superficial se había incrementado de forma notable. Así, se había pasado de establecimientos de menos de media hectárea a complejos de más de 5 hectáreas de parcela.

e) En lo que respecta a la oferta complementaria de ocio, dentro de la diversidad de infraestructuras edificadas en este último periodo, destacan, como otro factor de crecimiento urbano, los campos de golf por su número y superficie. Partiendo de los 7 campos de juego existentes en 1995, entre este año y 2009 se construyeron y pusieron en funcionamiento otros 17, llegando a los 24 actuales. Todo ello explica un incremento de $6 \mathrm{Km}^{2}$, a los que hay que sumar el de aquellas infraestructuras (oferta alojativa y residencial) asociadas a los mismos, conformando complejos más amplios denominados «espacios de golf» (Feo, 2007).

Con todo ello, la aplicación de una política turística articulada en torno a un proceso dual de contención del crecimiento y recualificación mediante nuevas infraestructuras, en medio de un ciclo económico expansivo, evidenció una mayor incidencia de la nueva construcción frente a la renovación de la existente (efectos derivados de la presión de lo inmobiliario), rompiendo con los principios de contención. Aun así, la infraestructura turística sólo había logrado explicar una parte de este crecimiento (aproximadamente $9,5 \mathrm{Km}^{2}$ de los 29,4 $\mathrm{Km}^{2}$ afectados por procesos de urbanización en las áreas turísticas).

6 En virtud del Decreto 10/2001, de 22 de enero, de estándares turísticos. Posteriormente modificado y ampliado por el Decreto 142/2010, de 4 de octubre, por el que se aprueba el reglamento de la actividad turística de alojamiento y se modifica el Decreto 10/2001, de 22 de enero, por el que se regulan los estándares turísticos. 


\section{Figura 4 \\ EJEMPLO DEL CAMBIO EN LA TIPOLOGÍA EDIFICATORIA DE LA OFERTA ALOJATIVA TURÍSTICA}

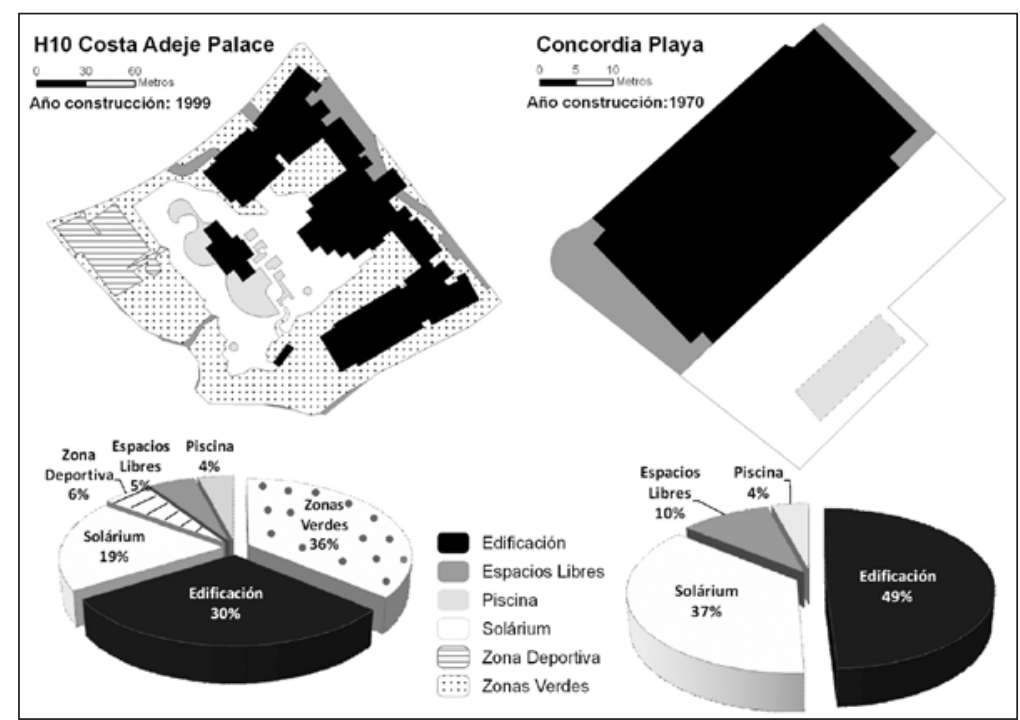

Fuente: Adaptado de Simancas y García, 2010; García, 2013.

En medio de una política de contención de la oferta alojativa turística (moratoria turística) en la que sólo se permitía la construcción de un número concreto de proyectos condicionados por una categoría mínima (4, 5 estrellas y 5 estrellas gran lujo) y estándares edificatorios de carácter más extensivo (hoteles horizontales), la oferta alojativa turística no llegó a crecer (en plazas y superficie) tanto como pudiera esperarse de las autorizaciones administrativas pre-existentes (Simancas, 2010). Por otro lado, en relación con la recualificación de las áreas turísticas y la diversificación de su oferta, la implantación de oferta complementaria de ocio dio lugar a la ocupación de importantes bolsas de suelo, siendo más significativo que el desarrollado por la oferta alojativa en este mismo periodo. Sin embargo, ambos, en su conjunto, no lograban explicar el considerable crecimiento que habían experimentado las áreas turística de litoral en Canarias en este último ciclo expansivo (García, 2013).

f) Para completar el modelo explicativo de estos crecimientos tuvo que tomarse en consideración el uso residencial de nueva edificación. Así, dentro de las áreas turísticas de litoral, a partir del mapa de ocupación del suelo, la delimitación territorial de la evolución y cambios en los usos del suelo, así como la estimación de habitantes y su localización en estos ámbitos, en su conjunto, facilitaron una primera aproximación al creciente peso que había experimentado el uso residencial-turístico en estos ámbitos, base que fundamentó posteriores trabajos en este sentido (ver Simancas y García, 2013b). Como resultado, $6 \mathrm{Km}^{2}$ se correspondían con nuevas urbanizaciones residenciales, a las que se les vinculaban otros $3,8 \mathrm{~km}^{2}$ de espacios libres, dotaciones 
y equipamientos. Asimismo, considerando la población empadronada, se estimó una concentración de 216.799 habitantes localizados dentro de alguna de las áreas turísticas de litoral analizadas, coincidiendo prioritariamente con población nacida en el extranjero, suponiendo el 10\% de los habitantes de Canarias en 2009.

En este sentido, en relación con las hipótesis planteadas, en el contexto del tercer boom turístico de Canarias, condicionado por una política turística de carácter dual, los datos evidenciaron un predominio de la edificación de nuevas infraestructuras frente a la renovación de la existente, lo cual puso en cuestión la contención del crecimiento de estos espacios turístico-urbanos. Lejos de una completa correspondencia con la infraestructura turística, el principal factor de crecimiento se vinculó con el uso residencial, que había quedado fuera de la regulación turística, evidenciándose una desviación de la inversión hacia la construcción de este tipo de infraestructura como respuesta a la política de contención de la oferta alojativa turística, entre otros factores. Con ello, aunque se había logrado contener el crecimiento de la oferta alojativa, se abrían nuevos interrogantes sobre los efectos que podrían tener en éstos ámbitos la considerable implantación de edificaciones residenciales (Simancas, 2010; García, 2013; Simancas y García, 2013a, 2013b).

Con la verificación de nuestras hipótesis y el apoyo del conocimiento obtenido del resto de líneas de investigación del proyecto, se logró concretar un modelo explicativo de los procesos de crecimiento turístico-inmobiliarios dentro de este nuevo ciclo expansivo, influenciado por una política turística de carácter intervencionista (ver figura 5), logrando así cumplir con los objetivos planteados.

\section{Figura 5 \\ ESQUEMA DEL MODELO EXPLICATIVO OBTENIDO DEL ANÁLISIS}

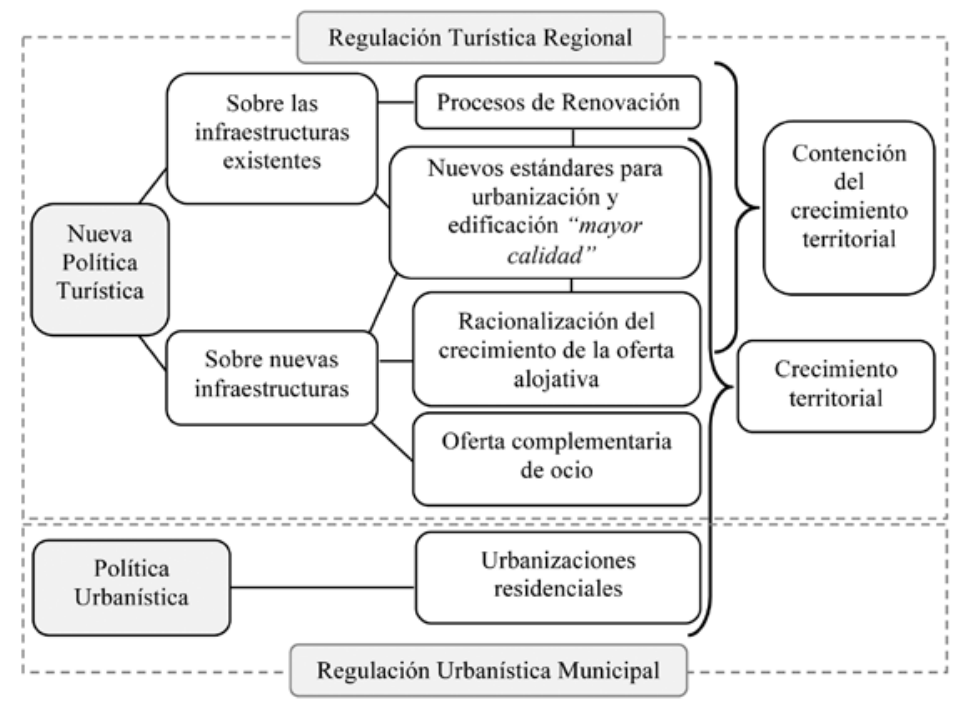

Fuente: García, 2013. 


\subsection{Fase 5. Transferencia de conocimientos}

Finalizado el proceso de investigación, al menos aquel que dio lugar a la necesidad de implementar el SIG, los conocimientos obtenidos del mismo se han difundido a través de diversas publicaciones, citadas aquellas referentes al uso del SIG a lo largo del artículo. El modelo explicativo obtenido, no sólo han enriquecido las bases teórica en torno a esta temática, sino que, además, el proceso de diseño e implementación del SIG, en el contexto de este tipo de investigación, ha realizado aportaciones a las bases prácticas. Con todo ello, se cierra un proceso cíclico ${ }^{7}$ que permite la articulación de un análisis científico riguroso, basado en la verificación de hechos observables mediante su medición sistemática, aportando interesantes resultados a un debate más amplio, de carácter multidisciplinar, mediante el uso de este tipo de sistemas de información.

Del mismo modo, los resultados de este trabajo han sentado las bases para el desarrollo de nuevas líneas de investigación que vuelven a ampliar las capacidades del sistema de información implementado, como a su vez ha verificado la validez de sus resultados. En este sentido, cabe citar el uso del SIG en 2011 para el desarrollo de los trabajos concernientes a la realización del Plan para la Rehabilitación de las Infraestructuras Turísticas de Puerto de $\mathrm{La} \mathrm{Cruz}^{8}$, en el que el SIG, para el caso concreto de esta área turística, sería actualizado y ampliado, incorporando datos en torno a la renovación de la oferta alojativa turística, las restricciones que posee la edificación a la hora de adaptarse a los nuevos estándares edificatorios, las particularidades de la estructura urbana, entre otros aspectos. Del mismo modo, la delimitación física de las áreas turísticas de litoral, así como el inventario y caracterización de la oferta alojativa turística de forma georeferenciada han sido utilizados como bases para la mejora de la estadística turística en Canarias (Hernández, et.al, 2012; Rodríguez, et.al, 2014; Hernández, et.al, 2014a; Hernández, et.al., 2014b). En concreto, a través de la unidad mixta de investigación entre La Universidad de La Laguna y el Instituto Canario de Estadística (ISTAC), en Abril de 2015 se hacían públicas, tanto la nueva estadística para entidades y núcleos turísticos (escala infra-municipal), así como la geolocalización del directorio de establecimientos alojativos turísticos del ISTAC ${ }^{9}$.

\section{CONCLUSIONES}

En el análisis de la dimensión territorial del turismo entran en juego un considerable número de variables observables y medibles que pueden aportarnos un conocimiento clave para la mejora de la planificación y gestión de estos ámbitos. En este sentido, las TIG aportan un enfoque y herramientas fundamentales para la articulación de un análisis de su componente espacial, obteniendo interesantes resultados.

7 Puede obtenerse más información sobre el esquema metodológico de desarrollo y su representación esquemática a través de los trabajos de Buzai y Baxendale; 2006 y Buzai, Baxendale y Cruz, 2009.

8 Puede accederse al documento a través del siguiente enlace: http://www.consorciopuertodelacruz.com/ planes/prit.pdf (última consulta:22 de abril de 2015)

9 Esta información puede ser consultada a través de la Infraestructura de Datos Espaciales de Canarias (IDECAN): http://visor.grafcan.es/visorweb/ contando además con un servicio Web Map Service (WMS) y el Sistema de Información de Geoestadística de Canarias del ISTAC: http://www.gobiernodecanarias.org/istac/ servicios/sigc.html 
Sosteniendo el orden, coherencia y rigurosidad del método científico, es posible el desarrollo de una investigación sobre geografía del turismo a través de esta herramienta. Tomando como referencia los fundamentos teóricos y metodológicos de la ciencia geográfica, se facilita un extraordinario control de un considerable número de variables espaciales. Así, teniendo en cuenta que ninguna herramienta, ni marco teórico-metodológico, es capaz de dar una respuesta completa a la multitud de interrogantes asociados a un fenómeno tan complejo como es el turístico, el uso de SIG, centrado en el análisis de variables espaciales cuantificables, aunque no nos puede aportar la totalidad de los elementos necesarios para la elaboración de un modelo explicativo, nos facilita un formidable control de las variables territoriales que aportan conocimientos vitales para su construcción. Mediante la medición sistemática de hechos territoriales contrastables es posible la obtención de un conocimiento del sistema territorial, que posteriormente puede ser incorporado a un debate más amplio, lo que facilita la comunicación con otras disciplinas.

En este sentido, ante el planteamiento de una investigación multidisciplinar, en este caso, sobre el impacto de las políticas públicas en materia turística durante el tercer boom turísticoinmobiliario de Canarias, la implementación de un SIG ha permitido obtener conocimientos fundamentales para su desarrollo. Así, haciendo uso de variables clave a escala insular (ocupación, planeamiento y población), como a escala área turística (ocupación, oferta alojativa, oferta complementaria, usos residenciales y población), se ha permitido identificar, dimensionar y caracterizar cada una de éstas, obteniendo mediciones sistemáticas que facilitan argumentos de peso en la construcción de un modelo explicativo sobre el tema tratado.

Sin romper con la estructura habitual de un proceso de investigación, la consideración de los antecedentes, el planteamiento del problema, el establecimiento de las cuestiones a resolver (preguntas de la investigación), las hipótesis que dirigirán el trabajo y los objetivos que definamos en este sentido, son una base fundamental para el diseño e implementación del SIG.

Sobre estas bases, la explotación de las variables seleccionadas, haciendo uso de la concatenación de herramientas prevista, siempre en función de los planteamientos de la investigación, permite su plena integración en la misma, en cuanto al análisis de las variables espaciales.

Con todo ello, la medición sistemática de los datos ha facilitado criterios objetivos con los que poder establecer unos límites físicos a los ámbitos que se han pretendido analizar, la identificación de un nuevo proceso de crecimiento turístico-inmobiliario en los mismos, localizándolo y dimensionándolo, además de permitir la identificación del conjunto de infraestructuras que lo ha protagonizado, facilitando datos sobre su entidad y relevancia en el proceso.

Este conocimiento, centrado en lo espacial y cuantificable, puede integrarse con el derivado de otras líneas de trabajo, permitiendo, como hemos visto, construir modelos explicativos más sólidos de aquellos procesos que se han desarrollado el espacio turístico y sus consecuencias territoriales.

En definitiva, las TIG abren todo un campo de análisis, en el que aún queda mucho por hacer, del que agentes públicos y privados pueden hacer uso en la mejora de los procesos de toma de decisión en planificación y gestión territorial del turismo, adquiriendo un mayor conocimiento de los procesos mediante la incorporación de las variables espaciales. 


\section{BIBLIOGRAFÍA}

ANTÓN I CLAVÉ, S. (1998): «La urbanización turística. De la conquista del viaje a la reestructuración de la ciudad turística», Documentos d'Anàlisi Geográfica, Universidad Autónoma de Barcelona, n 32, pp. 17-43.

ARTIGUES, A.A. y RULLÁN, O. (2007): «Nuevo modelo de producción residencial y territorio urbano disperso (Mallorca, 1998-2006)», en Scripta Nova, vol. XI, n 245, 1 de agosto de 2007. Universidad de Barcelona. Disponible en: http://www.ub.edu/ geocrit/sn/sn-24510.htm

BEAS SECALL, L. (2012): «Los planes de excelencia turística en España (1992-2006). Una apuesta por la revitalización de los destinos. Revisión de su implantación e impactos», en Scripta Nova, vol. XVI, n 411, 20 de agosto de 2012. Universidad de Barcelona. Disponible en: http://www.ub.edu/geocrit/sn/sn-411.htm

BLÁZQUEZ SALÓM, M y MURRAY MÁS, I. (2010): «Una geohistoria de la turistización de las Islas Baleares», El periplo sustentable. Universidad Autónoma del Estado de México, no 18, pp. 69-118.

BOSQUE SENDRA, J. (1999): Sistemas de información geográfica. Madrid, Ediciones Rialp.

BOSQUE SENDRA, J. (1999): «La ciencia de la información geográfica y la geografía», en Actas VII Encuentro de Geógrafos de América Latina, San Juan de Puerto Rico.

BURRIEL DE ORUETA, E.L. (2008): «La década prodigiosa del urbanismo Español (1997-2006)», en Scripta Nova, vol. Extra, n 270 , X Coloquio Internacional de Geocrítica, 26-30 de mayo de 2008. Universidad de Barcelona. Disponible en: http://www. ub.edu/geocrit/-xcol/383.htm

BUZAI, G.D. (2008): «Consideraciones sobre el rol científico de los sistemas de información geográfica a dos décadas de pensamientos sobre la geografía de Peter Gould», Huellas. Universidad Nacional de La Pampa, $\mathrm{n}^{\circ}$ 12, pp. 265-281.

BUZAI, G.D. (2010): «Geografía, organización del territorio y sistemas de información geográfica», GESIG-Universidad de Luján, nº 1, pp. 37-49.

BUZAI, G.D. y BAXENDALE, C.A. (2006): Análisis socioespacial con sistemas de información geográfica. Buenos Aires, Lugar Editorial.

BUZAI, G.D., BAXENDALE, C.A. y CRUZ, M.R. (2009): «Fases de un proyecto de investigación en estudios de geografía aplicada basados en el uso de sistemas de información geográfica», Fronteras, n ${ }^{\circ}$ 8, pp. 31-40.

CÁCERES MORALES, E. (2001): Génesis y desarrollo del espacio turístico en Canarias. Las Palmas de Gran Canaria: Universidad de Las Palmas de Gran Canaria. Gobierno de Canarias.

CAI, Q., RUSHTON, G., BHADRI, B., BRIGHT, E.A. y COLEMAN, P. (2006): «Estimating Small-Area Populations by Age and Sex Using Spatial Interpolation and Statistical Inference Methods», en Transaction in GIS, vol. 10. Págs. 577-598.

CAPEL, H. (2003): «¿Quo vadis Geographia? La geografía española y los concursos para la habilitación del profesorado universitario», en Biblio $3 W$, Revista Bibliográfica de Geografía y Ciencias Sociales, vol. VIII, n 469, 25 de octubre de 2003. Universidad de Barcelona. Disponible en: http://www.ub.edu/geocrit/b3w-469.htm 
CAPEL, H. (2005): «Las TIG en los concursos de habilitación para profesores titulares de geografía humana. Una cuestión nada anecdótica», en Biblio $3 W$, Revista Bibliográfica de Geografía y Ciencias Sociales, vol. X, nº 620, 15 de noviembre de 2005. Universidad de Barcelona. Disponible en: http://www.ub.edu/geocrit/b3w-620.htm

CAPEL, H. (2009): «Geografía en la red a comienzos del tercer milenio. Por una ciencia solidaria y en colaboración», en Biblio 3W, Revista Bibliográfica de Geografía y Ciencias Sociales, vol. XIV, $\mathrm{n}^{\circ}$ 313, 1 de febrero de 2010. Universidad de Barcelona. Disponible en: http://www.ub.edu/geocrit/sn/sn-313.htm

CES-CANARIAS. (2006): Las jerarquías territoriales de la actividad humana en Tenerife. Informe Anual. Consejo Económico y Social de Canarias. pp. 559-651.

CHOI, S., WANG, P., DELGADO, E., y RYU, S.H. (2007): «Monitoring Small Area Growth with GIS: An Application to the City of Los Angeles», ponencia presentada en la ESRI International User Conference. San Diego. California. pp 1-27.

CHUVIECO, E., BOSQUE, J., PONS, X., CONESA, C., SANTOS, J.M., GUITIÉRREZ, J., SALADO, M.J., MARTÍN, M.P., DE LA RIVA, J., OJEDA, J. y PRADOS, M.J. (2005): «¿Son las tecnologías de la información geográfica parte del núcleo de la geografía?», Boletín de la Asociación de Geógrafos Españoles, n 40, pp. 35-55.

CONSEJERÍA DE TURISMO Y TRANSPORTES. (2003): El turismo de golf en las islas Canarias. Consejería de Turismo y Transportes. Gobierno de Canarias.

DE SOUZA IGLESIAS, A. y BAUTE HERNÁNDEZ, L. (2002): «Las directrices de ordenación del turismo en la ordenación general del territorio», en Jornadas Técnicas sobre el avance de las directrices de ordenación del turismo de Canarias. San Cristóbal de La Laguna: Vicerectorado de Extensión Universitaria. Universidad de La Laguna. pp. 13-20.

DEL ROSARIO CRUZ, M. (2008): «Los sistemas de información geográfica como herramienta de disección y síntesis desde la perspectiva lógico-metodológica del proceso de investigación», en VV.AA. (Ed.): Anuario de la División Geografía 2008. Luján. Departamento de Ciencias Sociales. Universidad Nacional de Luján. pp. 299-309.

DOBSON, J.E. (1983): «Automated Geography», The Professional Geographer, n 2:35, pp. $135-143$.

DOBSON, J.E. (1993): «The Geographic Revolution: A Retrospective on the Age of Automated Geography», The Professional Geographer, n 4:45, pp. 431-439.

FRANCISCO DÍAZ, J.C (2003): Canarias, moratoria y REF. Santa Cruz de Tenerife, Ecopress comunicaciones.

FEO PARRONDO, F. (2001): «Los campos de golf en España y sus repercusiones en el sector turístico», Cuadernos de Turismo. Universidad de Murcia, nº 7, pp. 55-66.

FERNÁNDEZ DURÁN, R. (2006): «El tsunami urbanizador español y mundial». Boletín. Ciudades por un futuro más sostenible», en Boletín $C F+F, \mathrm{n}^{\circ} 38 / 39$. Disponible en: http://habitat.aq.upm.es/boletin/n38/arfer.html

GAJA I DÍAZ, F. (2008): «El “Tsunami urbanizador” en el litoral mediterráneo. El ciclo de hiperproducción inmobiliaria 1996-2006», en Scripta Nova, vol. XII, nº 270. Universidad de Barcelona. Disponible en: http://www.ub.edu/geocrit/sn/sn-270/sn-270-66.htm

GARCÍA CRUZ, J.I. (2013): El impacto territorial del tercer boom turístico de Canarias. Tesis doctoral. San Cristóbal de La Laguna, Universidad de La Laguna. 
GARCÍA CRUZ, J.I., y SIMANCAS CRUZ, M.R. (2011): «El paisaje de las áreas protegidas de Canarias», en Retos y perspectivas de la gestión del paisaje de Canarias. Reflexiones en relación con el $10^{a}$ aniversario de la firma del Convenio Europeo del Paisaje. Santa Cruz de Tenerife: Observatorio del Paisaje de Canarias, Gobierno de Canarias / Universidad Internacional Menéndez y Pelayo. pp. 248-269.

GÓMEZ DELGADO, M. (2005): Sistemas de información geográfica y evaluación multicriterio en la ordenación del territorio. Madrid, Ra-Ma.

GONZÁLEZ PÉREZ, J.M. (2010): «El reciclaje de la ciudad. La rehabilitación de espacios turísticos maduros en Mallorca», en Actas X Coloquio y jornadas de campo de geografía urbana, Bilbao. pp. 195-215.

GUEVARA, J.A. (1992): «Esquema metodológico para el diseño e implementación de un sistema de información geográfico», en Actas V Coloquio de Geografía Cuantitativa. Asociación de Geógrafos Españoles (AGE), Zaragoza, pp. 21-30.

GUTIERREZ PUEBLA, J. (2000): SIG: sistemas de información geográfica, Madrid. Síntesis.

HERNÁNDEZ MARTÍN, R. (2010): «Turismo y desarrollo en Canarias. Las bases para un nuevo modelo», en Destinos turísticos maduros ante el cambio. San Cristóbal de La Laguna, Instituto Universitario de Ciencias Políticas y Sociales. Universidad de La Laguna, pp. 281-305.

HERNÁNDEZ MARTÍN, R., GONZÁLEZ YÁNES, J. A., GONZÁLEZ MORA, Y., SIMANCAS CRUZ, M.R., RODRÍGUEZ RODRÍGUEZ, Y. y GARCÍA CRUZ, J.I. (2002): «Designing and analysing micro-destinations. A pilot study in the Canary Islands», en INRouTe $1^{\text {st }}$ Seminar on Regional Tourism: setting the focus. International Network on Regional Economics. Mobility and Tourism (INRouTe) / UNWTO / Università Ca'Foscari Venezia. Venice.

HERNÁNDEZ MARTÍN, R., SIMANCAS CRUZ, M.R., GONZÁLEZ YÁNES, J. A., RODRÍGUEZ RODRÍGUEZ, Y., GARCÍA CRUZ, J.I. y GONZÁLEZ MORA, Y. (2014a): «Identifying micro-destinations and providing statistical information. A pilot study in the Canary Islands». Current Issues in Tourism. pp. 1-20.

HERNÁNDEZ MARTÍN, R.; GONZÁLEZ YÁNES, J. A.; GONZÁLEZ MORA, Y.; RODRÍGUEZ RODRÍGUEZ, Y.; SIMANCAS CRUZ, M.R. y GARCÍA CRUZ, J. I. (2014b): «Analyzing tourism performance and impacts at local destinations: evidence fron the Canary Islands», en Second International Seminar on Regional Tourism: moving towards a regional TSA. The World Tourism Organization (UNWTO). CISET. Cooperative Research Centre in Tourism (CICtourGUNE). Veneto Regional Goverment.

KNOWLES, T. y CURTIS, S. (1999): «The market viability of European mass tourist destinations. A Post-Stagnation Life-Cycle Analysis», International Journal of Tourism Research vol. 1, 4, pp. 87-96.

LWIN, K. y MURAYAMA, Y. (2009): «A GIS approach to estimation of building population for micro-spatial Analysis», Transactions in GIS, vol. 13, n 4, pp. 401-414.

MAANTAY, J.A., MAROKO, A.R. y HERRMANN, C. (2007): «Mapping population distribution in the urban environment: the cadastral-based expert dasymetric system (CEDS)», Cartography and Geographic Information Science, 24, 2, pp. 77-102. 
PEÑA LLOPIS, J. (2006): Sistemas de información geográfica aplicados a la gestión del territorio. Entrada, manejo, análisis y salida de datos espaciales. Teoría y práctica para ESRI ArcGIS 9. Alicante, Editorial Club Universitario. Universidad de Alicante.

PINTO FARINA, D.M. y MONTE-MÓR, R.L. (2010): «Turismo, teorías económicas del espacio e Inhotim», en Actas XIV Seminario sobre economía minera. Universidad Federal de Minas Gerais.

RODRÍGUEZ RODRÍGUEZ, Y., HERNÁNDEZ MARTÍN, R., GONZÁLEZ YÁNES, J.A., GONZÁLEZ MORA,Y., SIMANCAS CRUZ, M.R. y GARCÍA CRUZ, J.I. (2014): «Delimitación de los micro-destinos turísticos en Canarias», en IX Seminario Canario de Economía, Empresa y Turismo. Facultad de Ciencias Económicas y Empresariales. Universidad de La Laguna.

RULLÁN, O. (1999): «Crecimiento y política territorial en las islas baleares (1995-2000)», Estudios Geográficos. Consejo Superior de Investigaciones Científicas (CSIC), nº 236, pp. 403-442.

RULLÁN, O. (2005): «Una técnica urbanística para contener el crecimiento residencial en espacios con fuerte presión inmobiliaria», en Sripta Nova, vol. IX, no 194, 1 de agosto de 2005. Universidad de Barcelona. Disponible en: http://www.ub.edu/geocrit/ $\mathrm{sn} / \mathrm{sn}-194-32 . \mathrm{htm}$

RULLÁN, O. (2010): «Los efectos territoriales de las dinámicas globales en unas islas turísticas mediterráneas: las Baleares», El periplo sustentable. Universidad Autónoma del Estado de México, no 18, pp. 119-160.

SÁNCHEZ MARTÍN, J.M., LECO BERROCAL, F., GUIRRÍA GASCÓN, J.L. y PÉREZ MARTÍN, M.N. (2000): «La planificación del turismo rural sostenible en Extremadura mediante SIG», en Actas Tecnologías geográficas para el Desarrollo Sostenible, pp. 544-573.

SIMANCAS CRUZ, M.R. (Coord.) (2006): La modelización de la estructura territorial del destino turístico Costa Adeje. Adeje, Ayuntamiento de Adeje.

SIMANCAS CRUZ, M.R. (2010): La moratoria turística y sostenibilidad territorial en destinos insulares consolidados. La experiencia de Canarias (2000 - 2010). Proyecto de Investigación. Acceso al cuerpo de profesores titulares de la Universidad de La Laguna en al Área de Geografía Humana (Inédito). San Cristóbal de La Laguna. Universidad de La Laguna.

SIMANCAS CRUZ, M.R. (2012): «Evaluando políticas públicas de renovación de destinos turísticos maduros: el proceso de reconversión turística de Canarias», en Renovación y restructuración de destinos en áreas costeras. Marco de análisis, procesos, instrumentos y realidades. Valencia. Universidad de Valencia. pp. 163-200.

SIMANCAS CRUZ, M.R., HORCAJADA HERRERA, T. y GARCÍA CRUZ, J.I. (2009): «La modelización territorial de los procesos de residencialidad en áreas turísticas consolidadas de litoral: El caso de costa Adeje (Tenerife)», en Turismo, urbanización y estilos de vida. Las nuevas formas de movilidad residencial. Icaria, Barcelona, pp. 315-333.

SIMANCAS CRUZ, M.R. y GARCÍA CRUZ, J.I. (2010): «El impacto territorial de las estrategias de mejora de la calidad de los destinos maduros: la aplicación de estánda- 
res edificatorios a los alojamientos turísticos», en Destinos turísticos maduros ante el cambio. San Cristóbal de La Laguna, Instituto Universitario de Ciencias Políticas y Sociales. Universidad de La Laguna, pp. 161-182.

SIMANCAS CRUZ, M.R. y GARCÍA CRUZ, J.I. (2013a): «La residencialidad: ¿la alternativa a la oferta alojativa extrahotelera de Canarias?», Turismo, Escuela de Turismo IRIARTE, $n^{\circ}$ 3-4, pp. 13-21.

SIMANCAS CRUZ, M.R. y GARCÍA CRUZ, J.I. (2013b): «La dimensión territorial de la residencialidad en las áreas turísticas de Canarias», Boletín de la Asociación de Geógrafos Españoles, nº 63, pp. 271-299.

SIMANCAS CRUZ, M.R., GARCÍA CRUZ, J.I., DORTA RODRÍGUEZ, A. y FALERO GONZÁLEZ, R.A. (2011): «El impacto territorial de la moratoria turística de Canarias», en Actas XXII Congreso de Geógrafos Españoles. Asociación de Geógrafos Españoles / Colegio de Geógrafos de España, Alicante, pp. 715-726.

TAPIADOR, F.J. (2006): «Las Tecnologías de Información Geográfica: Criticando al crítico. Una respuesta a Horacio Capel», en Biblio 3W, Revista Bibliográfica de Geografía y Ciencias Sociales, vol. X, no 648, 30 de abril de 2006. Universidad de Barcelona. Disponible en: http://www.ub.edu/geocrit/b3w-646.htm

TOMLINSON, R. (2007): Pensando en el SIG. Planificación del sistema de información geográfica dirigida a gerentes. Redlands, ESRI Press.

VERA REBOLLO, J.F. (Ed.) (1997): Análisis territorial del turismo. Barcelona, Ariel.

VERA REBOLLO, J.F. (Coord.) (2011): Análisis territorial del turismo y planificación de destinos turísticos. Valencia, Tirant Lo Blanch.

WU, S.S.; WANG, L; QIU, X. (2008): «Incorporation GIS bulding data and census housing statistics for sub-block-level population estimation», The Professional Geographer, 60:1, pp. 121-135.

ZURITA ESPINOSA, L. (2011): La gestión del conocimiento territorial. Madrid, Ra-Ma. 
